\title{
Organic matter accumulating in Aeh and Bh horizons of a Podzol - chemical characterization in primary organo-mineral associations
}

\author{
Michael W.I. Schmidt , Heike Knicker, Ingrid Kögel-Knabner
}

The chemical structure of soil organic matter from the eluvial (Aeh) and (illuvial) Bh horizon of a Podzol was studied in primary organo-mineral associations by ${ }^{13} \mathrm{C}$ CPMAS NMR spectroscopy and acid hydrolysis. In Podzols, organic matter is leached from the forest floor and Aeh horizons into the Bh horizon, where it is intimately associated with the mineral phase. In the Aeh horizon the majority of the residual organic matter was present in methylene structures, contributing $42 \%$ to the organic matter associated with the clay fraction. In the Ael horizon decreasing particle size was typically accompanied by increasing ratios alkyl $\mathrm{C}$-to-O-alkyl $\mathrm{C}$, suggesting increasing decomposition of polysaccharides for the residual organic matter. The illuvial Bh horizon, containing high proportions of iron- and aluminum-oxides and hydroxides, was higher in aromatic carbon, while polysaccharides were similar and methylene carbon were smaller than in the Aeh horizon. In the particle size separates proportions of polysaccharides were constant, resulting in decreasing ratios alkyl $\mathrm{C} / \mathrm{O}$-alkyl C. Proportions of hydrolyzable amino acids were larger in the Aeh horizon $(52 \%$ of the total $\mathrm{N})$ than in the Bh horizon $(21 \%)$, both for bulk soils and size separates. Our results suggested that in Bh horizons of Podzols, aromatic structures and also presumably labile structures like polysaccharides can be stabilized by organo-mineral associations.

\section{Introduction}

Soil organic matter (SOM) comprises plant, animal and microbial residues in all stages of decay, intimately mixed with inorganic soil components (Kögel-Knabner, 1993). SOM can be studied in primary organo-mineral associations obtained after complete dispersion of aggregates. Previous investigations of SOM associated with primary organo-mineral associations revealed a distinct trend from plant derived coarse particles to microbial derived fine particles, suggesting an increasing extent of decomposition (Turchenek and Oades, 1979). Nitrogen enrichment in finer size separates, was reflected by consistently lower
$\mathrm{C} / \mathrm{N}$ ratios, and supported the hypothesis of increasing degree of decomposition of plant residues (Christensen, 1996).

${ }^{13}$ C CPMAS NMR spectroscopy was applied to follow the extent of decomposition of SOM in particle size separates of A horizons from agricultural soils in Australia (Baldock et al., 1992, 1997). Sand size separates were dominated by $O$-alkyl $\mathrm{C}$, probably mainly due to polysaccharides in plant residues. Clay fractions were dominated by alkyl $\mathrm{C}$ which is considered to relate to a gradual accumulation of plant derived waxes and microbial methylene type structures. Contributions from aromatic $C$ reached a maximum in the silt size separate and decreased in the fine separate, whereas carboxyl $\mathrm{C}$ varied. Similar trends were found in a recent statistical analysis of published ${ }^{13} \mathrm{C}$ CPMAS NMR of mainly surface soil (A) horizons (Mahieu et al., 1999). Baldock et al. (1992) have ascribed these textural differences to two simultaneous processes, whose net effects change with 
particle size. The first mechanism was the physical and chemical breakdown of sand sized plant material reflected by increasing loss of $O$-alkyl C structures. The resulting lignin-rich debris contributed to the aromatic carbon maximum in silt sized separates. Size reduction and lignin degradation continued, resulting in highly altered aromatic matter intimately associated with clay minerals. The second process was accumulation of nitrogen as polysaccharides and lignins are sequentially converted via microbial biomass to a highly aliphatic residue, including appreciable polysaccharides. The majority of NMR spectroscopical informations on particle size fractions originate from surface (A) horizons, mainly under agricultural use (Mahieu et al., 1999). We are not aware of a NMR spectroscopical study on particle size separates from subsoil (B) horizons under forest use.

In the present study, particle size separates from $\mathrm{A}$ and $\mathrm{B}$ horizons of a Podzol under forest have been examined. Podzols exhibit a characteristic sequence of horizons created by strong leaching and acidity (Duchaufour, 1998). Podzols are poor in available nutrients, and have low $\mathrm{pH}$, which implies that biological homogenization is virtually absent. This results in well-defined profiles with thick organic horizons, overlying the mineral A horizon which is darkened in its upper portion by organic materials. The lower (eluvial) A horizon is almost white sand, resulting from acidic and organic-rich percolating water, which washes soluble and colloidal materials down the profile. The dark (illuvial) B horizon is a zone of net accumulation, where organic matter is intimately associated with metal oxyhydroxides. Podzols can act as chromatographic systems for percolating soluble and colloidal material, according to sorption intensity. Laboratory experiments showed that hydrophobic dissolved organic matter, mainly lignocellulose-derived, sorbs strongly, whereas the hydrophilic fraction, more labile structures, like free polysaccharides, sorb weakly (Guggenberger and Zech, 1993; Kaiser and Guggenberger, 2000; Kaiser and Zech, 1998). Strong sorptive interactions could stabilize organic matter against degradation.

The objective of the present study was to elucidate the chemical composition of the organic matter in the Aeh and Bh horizon of a Podzol in bulk soils and seven particle size separates. We used a suite of complementary methods, including elemental analysis, ${ }^{13} \mathrm{C}$ CPMAS NMR spectroscopy and hydrolyzable $\alpha$-amino acids.

\section{Materials and methods}

\subsection{Sampling sites}

The Podzol Flaesheim was situated in the southern Münsterland in Flaesheim, Germany, south of Haltern (coordinates: R ${ }^{25} 83575, \mathrm{H}^{57} 32175$, Topographical Sheet TK25 4209 Haltern). The height above see level was approximately $87 \mathrm{~m}$, slope $2^{\circ}$, north aspect. The mean annual precipitation was $800 \mathrm{~mm}$, and mean annual temperature $10^{\circ} \mathrm{C}$. The vegetation has been forest since the beginning of the 20th century, and was Pinus sylvestris at the time of sampling, forming a mor humus type.

\subsection{Sample pretreatment}

Soil description, sampling and classification were performed according to established procedures (FAO, 1994). Horizons were designated according to the German Soil Survey Description (AG-Boden, 1994). Bulk densities of the mineral horizons were determined gravimetrically in standardized steel rings after drying at $105^{\circ} \mathrm{C}$. Roots and visible plant remains were mechanically removed from mineral soil samples. After freezedrying, the soil aggregates were crushed and particles $>2 \mathrm{~mm}$ were removed by dry sieving. For chemical analysis an aliquot of the soil sieved to $<2 \mathrm{~mm}$ was ground in a ball mill for $10 \mathrm{~min}$. The $\mathrm{pH}$ was measured with a glass electrode in the supernatant of a mixture of $0.01 \mathrm{M} \mathrm{CaCl}_{2}$ and soil (2.5:1 based on mass).

\subsection{Particle size separation}

Two particle size separation procedures were used. Mineral horizons were analyzed for the particle size distribution of the mineral phase (Table 1) following the standard pipette/sieve method (Gee and Bauder, 1986). From the Aeh and Bh horizons we isolated seven particlesize separates, obtained by a combination of wet sieving and sedimentation (Table 2) after complete dispersion by ultrasound (Schmidt et al., 1999). Briefly, we calibrated the ultrasonic energy of an ultrasonic titanium probe with a diameter of $19 \mathrm{~mm}$ (Labsonic U, Braun Melsungen, Germany), and applied $440 \mathrm{~J} \mathrm{ml}^{-1}$ of suspension to

Table 1

Description of the Haplic Podzol

\begin{tabular}{|c|c|c|c|c|c|c|c|c|}
\hline \multirow[t]{2}{*}{ Horizon $^{\mathrm{b}}$} & \multirow[t]{2}{*}{$\begin{array}{l}\text { Depth } \\
\mathrm{cm}\end{array}$} & $\mathrm{pH}$ & $\mathrm{C}_{\mathrm{org}}$ & $\begin{array}{l}\text { Total } \\
\mathrm{N}\end{array}$ & $\mathrm{C}: \mathrm{N}$ & Sand & Silt & Clay \\
\hline & & \multicolumn{4}{|c|}{$\mathrm{g} \mathrm{kg}^{-1}$} & \multicolumn{3}{|c|}{ Mass $\%{ }^{c}$} \\
\hline $\mathrm{L}$ & +13 & $-^{\mathrm{a}}$ & 482.0 & 13.0 & 37 & - & - & - \\
\hline Of & +10 & - & 334.1 & 13.5 & 25 & - & - & - \\
\hline $\mathrm{Oh}$ & +5 & - & 258.0 & 9.7 & 27 & - & - & - \\
\hline Aeh & 12 & 3.1 & 14.5 & 0.4 & 36 & 92.4 & 6.5 & 1.3 \\
\hline $\mathrm{Ae}$ & 25 & 3.3 & 3.1 & 0.2 & 16 & 92.2 & 8.5 & 0.3 \\
\hline $\mathrm{Bh}$ & 31 & 2.9 & 34.5 & 1.0 & 35 & 87.1 & 8.9 & 4.1 \\
\hline Bs & 35 & 3.4 & 13.6 & 0.6 & 23 & 85.0 & 11.4 & 3.7 \\
\hline Bsv & 140 & 4.0 & 1.2 & 0.1 & - & 95.9 & 2.3 & 1.8 \\
\hline $\mathrm{Bv}$ & $>140$ & 4.2 & 0.5 & 0.1 & - & 96.1 & 1.2 & 0.6 \\
\hline
\end{tabular}

\footnotetext{
a Not determined.

b Horizon designations were according to AG-Boden (1994).

c Results obtained by standard particle size analysis (Gee and Bauder, 1986).
} 
obtain complete dispersion of the samples. By wet sieving, the suspension was separated into three sand separates $(630-2000,200-630$ and $63-200 \mu \mathrm{m})$. The clay separate $(<2 \mu \mathrm{m})$ and three silt separates $(20-63,6-20$ and $2-6 \mu \mathrm{m})$ were obtained by gravity sedimentation, and were recovered from the suspensions by filtration (cellulose nitrate, $0.45 \mu \mathrm{m}$ ). This procedure yields organo-mineral particle size separates, and a soluble fraction. The fraction $<0.45 \mu \mathrm{m}$ was collected, concentrated with a rotatory evaporator, and freeze dried. Alterations of the chemical structure of organic matter due to ultrasonication and subsequent ball milling were expected to be small (Schmidt et al., 1997a).

\subsection{Elemental analysis}

Carbon and nitrogen content of the bulk soils and the various separates were determined in duplicate with a Leco CNS 2000. The content of dissolved organic carbon was determined with a Shimadzu TOC 5050 Analyzer.

Table 2

Mass distribution, concentration and distribution of carbon and nitrogen for the particle size separates of different horizons

\begin{tabular}{|c|c|c|c|c|c|c|}
\hline Horizon $^{\mathrm{b}}$ & Mass $^{\mathrm{c}}$ & $\mathrm{C}_{\text {org }}$ & & $\mathrm{N}$ & & $\mathrm{C}: \mathrm{N}$ \\
\hline & $\begin{array}{l}\% \text { of } \\
\text { bulk }\end{array}$ & $\mathrm{g} \mathrm{kg}^{-1 \mathrm{~d}}$ & $\begin{array}{l}\% \text { of } \\
\text { bulk }\end{array}$ & $\mathrm{g} \mathrm{kg}^{-1 \mathrm{~d}}$ & $\begin{array}{l}\% \text { of } \\
\text { bulk }\end{array}$ & \\
\hline
\end{tabular}

\begin{tabular}{lrrrrrl}
\hline Aeh & & & & & & \\
Coarse sand & 0.8 & 1.8 & 0.1 & 0.2 & 0.4 & - a \\
Medium sand & 33.1 & 0.4 & 0.9 & $<0.1$ & 0.9 & - \\
Fine sand & 49.3 & 0.6 & 2.1 & $<0.1$ & 1.3 & - \\
Coarse silt & 8.0 & 2.7 & 1.5 & $<0.1$ & 2.1 & - \\
Medium silt & 2.2 & 102.5 & 16.1 & 2.7 & 15.3 & 38 \\
Fine silt & 2.0 & 263.8 & 37.6 & 5.7 & 29.4 & 46 \\
Clay & 1.5 & 393.7 & 42.0 & 10.9 & 42.2 & 36 \\
DOM $^{\text {e }}$ & - & - & 1.0 & - & - & - \\
\% Recovery & 96.9 & & 101.3 & & 91.5 & \\
Bh & & & & & & \\
Coarse sand & 0.7 & 3.5 & 0.1 & $<0.1$ & $<0.1$ & - \\
Medium sand & 32.1 & 1.3 & 1.3 & $<0.1$ & 0.3 & - \\
Fine sand & 42.8 & 1.8 & 2.4 & $<0.1$ & 0.5 & - \\
Coarse silt & 7.1 & 4.6 & 1.0 & $<0.1$ & $<0.1$ & - \\
Medium silt & 3.7 & 196.3 & 22.4 & 5.5 & 21.6 & 36 \\
Fine silt & 3.7 & 285.1 & 32.5 & 8.4 & 33.0 & 34 \\
Clay & 3.8 & 272.7 & 31.9 & 10.4 & 42.0 & 26 \\
DOM & 0.2 & 348.6 & 2.9 & 14.7 & - & 24 \\
\% Recovery & 94.1 & & 94.5 & & 97.5 & \\
\hline
\end{tabular}

${ }^{a}$ Not determined.

b AG-Boden (1994).

c Particle size separates obtained after ultrasonic dispersion as described in Section 2.

${ }^{\mathrm{d}}$ Expressed as $\mathrm{g} \mathrm{kg}^{-1}$ bulk soil or size separate.

e Dissolved organic matter: after filtration the content of dissolved organic carbon was determined for the separate $<0.45 \mu \mathrm{m}$ with an aliquot of the solution, and from this data per cent of total organic carbon was calculated.

\section{5. ${ }^{13}$ C CPMAS NMR spectroscopy}

The solid-state ${ }^{13} \mathrm{C}$ NMR spectra were obtained on a Bruker MSL $100(25.178 \mathrm{MHz})$. The cross polarization and magic angle spinning technique (CPMAS) (Schaefer and Stejskal, 1976) was applied with a spinning speed of $4 \mathrm{kHz} .{ }^{13} \mathrm{C}$ NMR experiments were carried out with a contact time of $1.0 \mathrm{~ms}$, a $90^{\circ}{ }^{1} \mathrm{H}$-pulse width of $6.6 \mathrm{~ms}$ and a pulse delay of 100-600 ms (Knicker, 1993). Before Fourier transformation, we applied line broadenings between 20 and $100 \mathrm{~Hz} \cdot{ }^{13} \mathrm{C}$ chemical shifts (Table 3) are reported relative to tetramethylsilane $(=0 \mathrm{ppm})$. For the relative intensity distribution of the solid-state ${ }^{13} \mathrm{C}$ CPMAS NMR, the precision is approximately $10 \%$ of the signal intensity, depending on the signal-to-noise ratio. However, for spectra with low signal-to-noise ratios higher deviations can occur for the regions $220-160$ and 45 to $-10 \mathrm{ppm}$ (Knicker, 1993). To remove paramagnetic material, and to improve the resolution of the spectra, all bulk and particle size separates from mineral horizons were treated with hydrofluoric acid (HF 10\%) prior to NMR analysis (Schmidt et al., 1997b). This study indicated that chemical alterations due to HF treatment were small.

\subsection{Hydrolyzable $\alpha$-amino acids}

The content of hydrolyzable amino acid nitrogen was determined with the colorimetric ninhydrin method (Stevenson, 1982). Between 0.2 and $0.5 \mathrm{~g}$ of the sample was hydrolyzed $\left(6 \mathrm{~N} \mathrm{HCl}\right.$ /formic acid) for $12 \mathrm{~h}$ at $110^{\circ} \mathrm{C}$ in duplicate. The relative standard deviation for the determination of amino acid-N was $4.2 \%(n=33)$ and for the colorimetric analysis $4.4 \%(n=69)$. The precision of the whole method was $\pm 0.080 \mathrm{~g}$ amino acid nitrogen/ $\mathrm{kg}$ soil dry weight.

Table 3

Chemical shift assignment of peaks in the solid-state ${ }^{13} \mathrm{C}$ CPMAS NMR spectra (referenced to tetramethylsilane $=0$ ppm) (Lüdemann and Nimz, 1973; Wilson, 1987)

\begin{tabular}{ll}
\hline ppm & Assignment \\
\hline $0-45$ & Alkyl-C \\
$45-110$ & $O$-Alkyl-C \\
$45-60$ & Aliphatic C-N, methoxyl \\
$60-95$ & Alkyl- $O$ (carbohydrates, alcohols) \\
$95-110$ & Acetal and ketal carbon (carbohydrates) \\
$110-160$ & Aromatic-C \\
$110-140$ & Aryl-H and aryl-C carbons \\
$140-160$ & Aryl-O and aryl-N carbons \\
$160-220$ & Carbonylic-C/carboxylic-C \\
$160-180$ & Carboxyl and amide carbons \\
$180-220$ & Aldehyde and ketone carbons
\end{tabular}




\section{Results and discussion}

\subsection{Physical characteristics and elemental composition}

The characteristic features of Podzols are eluvial horizons (Aeh, Ae), overlying illuvial horizons where humic material (Bh) and sesquioxidic material (Bs) like iron- and aluminum-oxides and hydroxides accumulate. The Podzol studied here had a sandy texture (Table 1) throughout the profile ( $85-96 \%$ sand) with characteristic, elevated silt and clay contents in the $\mathrm{Bh}$ horizon. Organic carbon, and $\mathrm{pH}$ varied within the range expected for Podzols under forest (Rehfuess, 1990). In the organic layers (L, Of, Oh) carbon and nitrogen contents and $\mathrm{C}: \mathrm{N}$ ratios decreased with depth (Table 1), indicating an increased degree of decomposition of organic matter. Compared to other Podzols (Rehfuess, 1990) carbon and nitrogen contents were slightly lower in the organic horizons. Mineral layers showed characteristic small carbon and nitrogen contents in the eluvial Aeh horizon (C: $14.5 \mathrm{~g} \mathrm{~kg}^{-1}$ air dry soil, and $\mathrm{N}: 0.4 \mathrm{~g} \mathrm{~kg}^{-1}$ ). The illuvial Bh horizon contained more organic carbon (Bh: $34.5 \mathrm{~g}$ carbon $\mathrm{kg}^{-1}$ ).

Table 2 gives the mass, organic $\mathrm{C}$ and $\mathrm{N}$ concentration and content results for the particle size separates of the Aeh, and Bh horizons, obtained using ultrasonic dispersion. Mass proportions of the separates corresponded well with those obtained by standard particle size analysis (Table 1), except for slightly smaller yields for sand separates. This indicated a more effective dispersion of sand particles by ultrasound compared to standard analysis and was observed previously (Schmidt et al., 1999). The particle size distribution revealed patterns with only minor variations between A and B horizons. Sand size particles dominated, whereas $<20 \mu \mathrm{m}$ sized particles contributed little (Aeh: $\leqslant 5.7 \%$, and $\mathrm{Bh}: \leqslant 11.2 \%$ ) to the total soil mass. Carbon and nitrogen concentrations showed opposite trends with largest concentrations in $<20 \mu \mathrm{m}$ separates. Despite their low mass, these three separates contributed the majority to the total soil organic matter, both for organic carbon (Aeh: 95.7\%, Bh: 86.8\%) and for nitrogen (Aeh: $86.9 \%$, and Bh: 96.6\%). Compared to previous studies on size separates summarized by Christensen (1992), the observed pattern could be considered typical of sandy soils, although carbon and nitrogen concentrations were higher than those reported for agricultural soils. In previous studies carbon-to-nitrogen ratios $(\mathrm{C}: \mathrm{N})$ typically decreased from coarse to fine separates, suggesting an increasing extent of decomposition. In the Podzol studied here, $\mathrm{C}: \mathrm{N}$ ratios were lowest in the clay separates. C:N ratios for the $>20 \mu \mathrm{m}$ separates could not be calculated due to their low nitrogen contents.

\section{2. ${ }^{13}$ C CPMAS NMR spectroscopy of bulk soils}

${ }^{13} \mathrm{C}$ CPMAS NMR spectra of the Aeh and Bh horizon were obtained for bulk soils (Fig. 1a and g). The chemical shift assignments (ppm) are given in Table 3. Spectra of the bulk Aeh and Bh horizons (Fig. 1a and g) showed signals at $33 \mathrm{ppm}$ in the alkyl-C region (45 to $-10 \mathrm{ppm}$ ), which may be attributed to methylene carbon. Resonances in the $O$-alkyl region $(60-110 \mathrm{ppm})$ indicated the presence of alcoholic or ether structures; the signal at 72 ppm corresponded to ring C-5, C-3 and C-2 carbons of polysaccharides. The resonance at $106 \mathrm{ppm}$ was attributed to the anomeric carbon in polysaccharides. Signals in the $\mathrm{sp}^{2}$-hybridized carbon region $(160-110$ $\mathrm{ppm}$ ) indicated the presence of protonated and C-substituted aryl carbon $(110,130 \mathrm{ppm})$ and O-substituted aromatic carbon (150 ppm), typically present in lignin, cutin and condensed tannin (Preston et al., 1997). In the carboxyl C region (220-160 ppm) broad signals attributable to carboxyl carbon, amide and ester structures were observed (Preston et al., 1982; Preston and Schnitzer, 1984). Differences in signal intensities between Aeh and $\mathrm{Bh}$ horizon in carbon species were largest for aromatic $\mathrm{C}$ and alkyl C. Relative contributions from aromatic $\mathrm{C}$ in the Aeh horizon (19\% of the total signal intensity) were lower than in the Bh horizon $(29 \%)$. The opposite was true for alkyl $\mathrm{C}$, with higher signal intensities for the Aeh horizon (37\%) than for the Bh horizon (28\%). These results are consistent with the experimental evidence that hydrophobic aromatics sorb more strongly to metal oxides than hydrophilic fractions like polysaccharides (Kaiser and Guggenberger, 2000). For carboxyl C and $O$-alkyl C differences were less pronounced. The spectra generally were similar to those observed for other natural Podzols (Hempfling et al., 1987; Skjemstad et al., 1992).

\section{3. ${ }^{13}$ C CPMAS NMR spectroscopy of particle size separates}

Particle size separates $<63 \mu \mathrm{m}$ contained the majority of the total organic carbon present in the Aeh horizon $(97.2 \%)$ and $\mathrm{Bh}$ horizon $(87.8 \%)$, and were investigated by ${ }^{13} \mathrm{C}$ CPMAS NMR spectroscopy (Fig. 1b-e, h-k). Sand sized separates, however, were too low in carbon content to obtain well resolved spectra, even after HF treatment.

The spectra of the coarse silt separates of the Aeh and $\mathrm{Bh}$ horizon (Fig. 1b, h) revealed signals for alkyl C (33 ppm), $O$-alkyl C (72, 89 and partly $106 \mathrm{ppm})$, carboxyl groups (175 ppm), and aromatic C, probably from lignin units. The silt separates of the Bh horizon (Fig. 1h, i, j) showed signals at 106, 130 and $116 \mathrm{ppm}$ with weak shoulders at $150 \mathrm{ppm}$. The peak at 106 may partly derive from C-1 and C-6 of syringyl units, but may be overlapped by the 115-120 ppm resonances of the C-2 and C6 in guaiacyl units and the anomeric carbon of polysaccharides. The resonance at $148 \mathrm{ppm}$ could be related to $\mathrm{C}-3$ carbon in guaiacyl units. The resonance at 135 ppm has contributions from C-1 and C-4 carbons in syringyl and $\mathrm{C}-1$ in guayacyl units. The shoulder at 153 may be due to $\mathrm{C}-3$ and $\mathrm{C}-5$ aryl- $O$ carbons of syringyl units. 

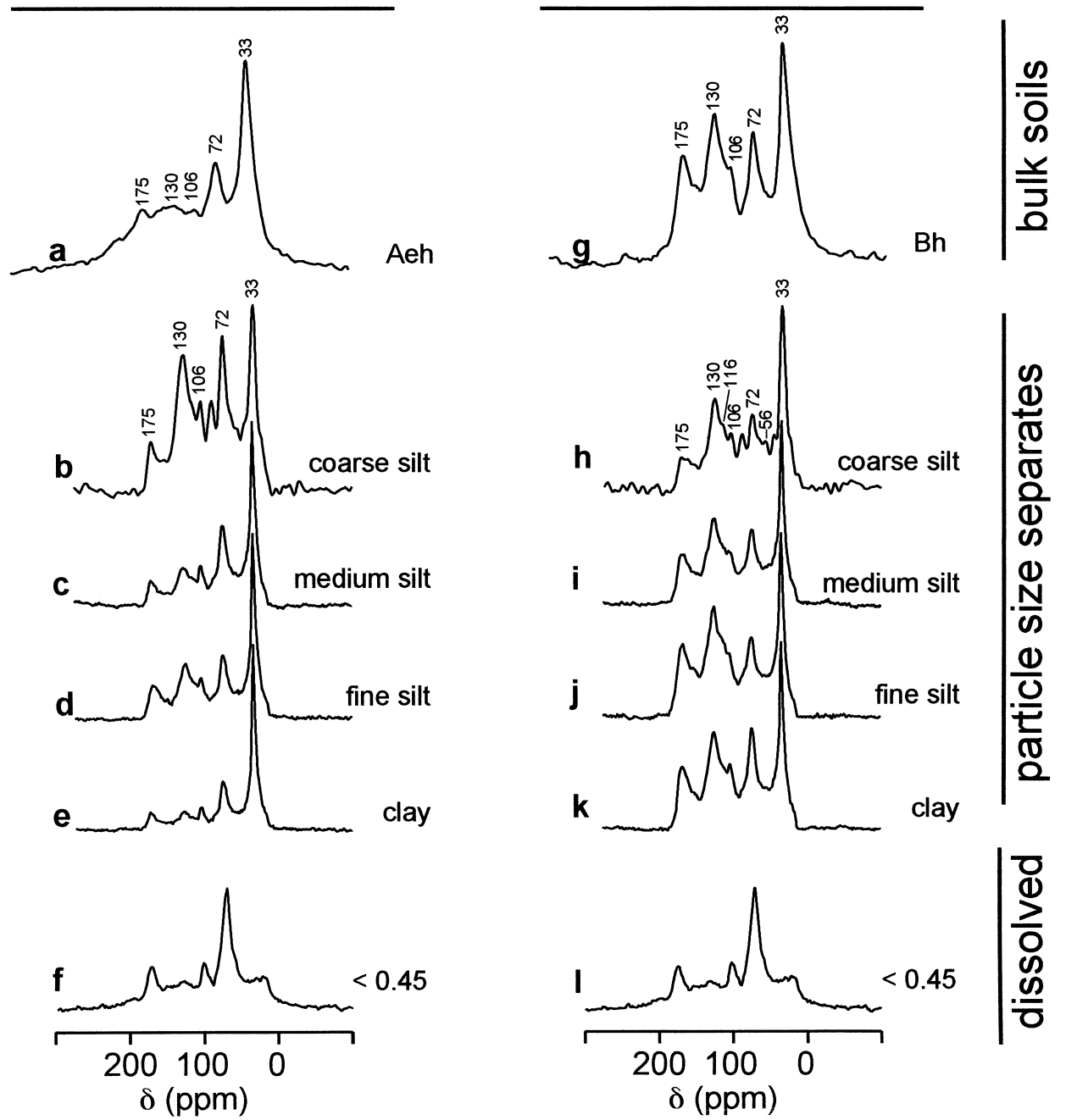

Fig. $1 .{ }^{13} \mathrm{C}$ CPMAS NMR spectra of the Aeh and Bh horizon and of the $<63 \mu \mathrm{m}$ particle size separates from Podzol Flaesheim. The particle size separates were clay $(<2 \mu \mathrm{m})$, fine silt $(2-6 \mu \mathrm{m})$, medium silt $(6-20 \mu \mathrm{m})$, coarse silt $(20-63 \mu \mathrm{m})$. The dissolved fraction $(<0.45 \mu \mathrm{m})$ was organic matter released during the particle size fractionation procedure.

Previous work on peats, organic soil horizons, and particle size fractions of agricultural A horizons showed that the ratio alkyl $\mathrm{C}-$ to- $O$-alkyl $\mathrm{C}$ increased when decomposition proceeded (Baldock et al., 1992, 1997). The increasing ratio can be interpreted as an increasing degree of decomposition of polysaccharides from plants, and an enrichment of methylene structures by the microbial biomass. To visualize this trend, we calculated the ratio alkyl C-to- $O$-alkyl $\mathrm{C}$ in Table 4 . In progressing from coarse silt $(D: 0.64)$ to the clay sized separate $(D$ : 1.53 ) the ratio $D$ increased consistently, suggesting an increasing degree of decomposition in agreement with the decreasing $\mathrm{C} / \mathrm{N}$ ratios (Table 2). Intensities for aromatic $\mathrm{C}$ peaked in the silt sized separate, while signals for carboxyl C varied (6-9\%).
The organic matter associated with the size separates obtained from the illuvial Bh horizon, however, revealed a completely different pattern in two aspects. First, size separates from the $\mathrm{Bh}$ horizon had larger intensities in the chemical shift region of aromatic carbon (34-40\% of the total signal intensity) than those from the Aeh horizon $(18-35 \%)$, similar to spectra of the bulk soils. Second, in progressing from coarse to fine particle size separates, relative signal intensities of $O$-alkyl $\mathrm{C}$ were constant, whereas intensities from alkyl C decreased (Table 4). This trend was reflected by consistent decreases in the value of $D$ from coarse silt ( $D: 0.97)$ to clay $(D: 0.71)$ separates. The changes in $D$ values were in striking contrast to trends observed for the Aeh horizon and those reported for previous studies, as summarized by Baldock et al. (1997). 
Table 4

Relative areas of peaks in ${ }^{13} \mathrm{C}$ MAS NMR spectra of bulk soils and particle size separates from both Podzols

\begin{tabular}{|c|c|c|c|c|c|}
\hline \multirow[t]{2}{*}{ Sample } & \multicolumn{2}{|c|}{ Carboxylic C Aromatic C } & \multicolumn{3}{|c|}{$O-$ alkyl C Alkyl C $D^{\mathrm{b}}$} \\
\hline & \multicolumn{5}{|c|}{$\%$ of total signal intensity ${ }^{a}$} \\
\hline \multicolumn{6}{|c|}{ Bulk soil } \\
\hline Aeh & 15 & 19 & 30 & 37 & 1.23 \\
\hline $\mathrm{Bh}$ & 14 & 29 & 29 & 28 & 0.97 \\
\hline \multicolumn{6}{|c|}{ Aeh/size separates } \\
\hline $20-63$ & 6 & 35 & 36 & 23 & 0.64 \\
\hline $6-20$ & 6 & 24 & 36 & 34 & 0.94 \\
\hline $2-6$ & 8 & 31 & 28 & 33 & 1.18 \\
\hline $0.45-2$ & 6 & 18 & 30 & 46 & 1.53 \\
\hline$<0.45$ & 14 & 18 & 42 & 27 & 0.64 \\
\hline \multicolumn{6}{|c|}{ Bh/size separates } \\
\hline $20-63$ & 6 & 34 & 31 & 30 & 0.97 \\
\hline $6-20$ & 10 & 36 & 29 & 25 & 0.86 \\
\hline $2-6$ & 12 & 40 & 27 & 21 & 0.87 \\
\hline $0.45-2$ & 10 & 37 & 31 & 22 & 0.71 \\
\hline$<0.45$ & 17 & 20 & 42 & 21 & 0.50 \\
\hline
\end{tabular}

a Data in per cent of total signal intensity (alkyl C 10 to 45 ppm, $O$-alkyl C 45 to $110 \mathrm{ppm}$, aromatic C 110 to $160 \mathrm{ppm}$, carboxyl C 160 to $220 \mathrm{ppm})$.

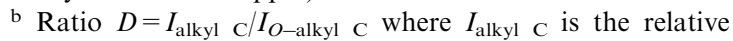
signal intensity in the chemical shift region for alkyl $\mathrm{C}$ (45 to $-10 \mathrm{ppm})$, and $I_{O-\text { alkyl C }}$ is the intensity in the $O$-alkyl C region (110 to $45 \mathrm{ppm}$ ).

In the clay sized separates, a major proportion of the $O$ alkyl C (31\%) was probably present as polysaccharides, which was concluded from the distinct signal centered around $72 \mathrm{ppm}$ in combination with the resonance at $106 \mathrm{ppm}$. Methylene structures, indicated by the distinct peak at $33 \mathrm{ppm}$, contributed less (22\%) to the total signal intensity.

The fact that the clay fraction, containing most of the oxides, had a large proportion of polysaccharide $\mathrm{C}$ in addition to aromatic $\mathrm{C}$, is not consistent with results from laboratory experiments, which suggest that aromatic dissolved organic matter in percolating water sorb stronger than other fractions (Guggenberger and Zech, 1993; Kaiser and Zech, 1998; Kaiser and Guggenberger, 2000). Sorption of dissolved organic matter to soils and oxides resulted in a preferential binding of aromatic structures and a discrimination of polysaccharides and methylene structures (Kaiser et al., 1997). Sorptive preservation of organic matter should result in a relative accumulation of aromatic structures in the clay fraction of the Bh horizon. This, however, was not the case. The fact that presumably labile polysaccharides were present in the clay sized separate could be attributed to microbial decay of sorbed organic matter and subsequent accumulation of microbial remains. Aliphatic compounds in $\mathrm{Bh}$ horizons of forest soils could also originate from root input (Kögel-Knabner and Hatcher, 1989; Riederer et al., 1993; Nierop, 1998). Limited quantitative reliability of ${ }^{13} \mathrm{C}$ CPMAS NMR spectra was probably less important, because all samples were treated with hydrofluoric acid, effectively removing paramagnetic material (Schmidt et al., 1997b).

The organic matter from the Aeh and Bh horizon released a water-soluble fraction $<0.45 \mu \mathrm{m}$ during the particle size separation procedure (Table 2). The Aeh horizon produced less soluble organic matter $(1.0 \%$ of the total organic carbon) than the Bh horizon $(2.9 \%)$. Both fractions yielded almost identical ${ }^{13} \mathrm{C}$ NMR spectra (Fig. 1f and 1) typical for polysaccharides. This was demonstrated by dominant peaks at $72 \mathrm{ppm}$ accompanied by signals at $106 \mathrm{ppm}$. In both samples $O$-alkyl C contributed the majority $(42 \%)$ to the total signal intensities, followed by alkyl C (Aeh: 27\%, Bh: 21\%). Distinct peaks were observed in the carboxyl region, whereas a broad set of signals contributing only $18-20 \%$ to the total signal intensity was observed in the aromatic region. The NMR spectra suggested that the water soluble organic matter released from the Aeh and Bh horizon was probably very similar in chemical structure, and showed little contribution from aromatic carbon. This was consistent with previous work that found preferential desorption of compounds with low aromaticity (Kaiser and Zech, 1998). The relative proportion of organic carbon released was larger in the Bh horizon than in the Aeh horizon. However, it is not clear if the organic matter released during the particle size separation procedure reflects solubility in situ directly.

\subsection{Hydrolyzable $\alpha$-amino acids}

Hydrolyzable $\alpha$-amino acids were characterized in bulk soils and in particle size separates (Table 5). Due to low nitrogen contents of the coarse separates only $<20 \mu \mathrm{m}$ separates were studied. To compare $\alpha$-amino acid distribution in samples differing in total nitrogen content, we report results also as per cent of total N. In the bulk soils contributions of hydrolyzable $\alpha$-amino acids to the total

Table 5

Hydrolyzable amino acids expressed as per cent of total nitrogen and (in parentheses) as concentration (g nitrogen $\mathrm{kg}^{-1}$ size separate or bulk soil). The particle size separates were clay $(<2$ $\mu \mathrm{m})$, fine silt $(2-6 \mu \mathrm{m})$, medium silt $(6-20 \mu \mathrm{m})$

\begin{tabular}{|c|c|c|c|c|}
\hline \multirow[t]{3}{*}{ Horizon } & \multicolumn{3}{|l|}{ Size separate } & \multirow[t]{3}{*}{ Bulk soil } \\
\hline & Medium silt & Fine silt & Clay & \\
\hline & \multicolumn{3}{|c|}{$\begin{array}{l}\text { Mass per cent of total nitrogen } \\
\text { (in parentheses concentration } / \mathrm{g} \mathrm{kg}^{-1} \text { ) }\end{array}$} & \\
\hline Aeh & $31(2.7)$ & $34(5.7)$ & $43(8.4)$ & $52(0.4)$ \\
\hline $\mathrm{Bh}$ & $23(5.5)$ & $20(8.4)$ & $21(10.4)$ & $21(1.0)$ \\
\hline
\end{tabular}


soil nitrogen were higher in the A horizon (52\%) than in the B horizon (21\%), which was similar to results reported for Canadian Podzols (Sowden, 1959). Yields in the particle size separates reflected results obtained for bulk soils. Proportions of hydrolyzable $\alpha$-amino acids were larger in the separates obtained from the Aeh horizon $(31-43 \%$ of the total $\mathrm{N})$ than in those from the Bh horizon (20-23\%), confirming previous results (Catroux and Schnitzer, 1987; Watson and Parsons, 1974). Standard acid hydrolysis releases only a part of the organic nitrogen in bulk soils and particle size separates. ${ }^{15} \mathrm{~N}$ CPMAS NMR spectroscopy allowed the nature of nitrogen in the soil matrix to be investigated without chemical extraction. The particle size separates investigated here were previously characterized using ${ }^{15} \mathrm{~N}$ NMR (Knicker et al., 1999). Between 60 and $90 \%$ of the identified nitrogen in the particle size separates was assigned to amides most probably derived from peptidelike structures. Differences between Aeh and Bh horizon were small for corresponding size fractions. Proportions of hydrolyzable $\alpha$-amino acids were (i) generally smaller than those detectable with ${ }^{15} \mathrm{~N}$ NMR, and (ii) smaller in the Bh horizon than in the Aeh horizon. It seemed that stabilization of organic matter against hydrolytic attack was largest in the $\mathrm{Bh}$ horizon.

\section{Conclusions}

A combination of elemental analysis, solid-state ${ }^{13} \mathrm{C}$ NMR spectroscopy and acid hydrolysis was used to study the distribution and chemical structure of organic matter in the Aeh and Bh horizon of a Podzol. In the Bh horizon organic matter and iron- and aluminum oxihydroxides accumulated. Stabilization of organic matter was supposed to occur by preferential binding of aromatic structures over labile structures like methylene and polysaccharide structures, as concluded from laboratory experiments (Kaiser and Guggenberger, 2000). In the Aeh horizon the majority of the organic matter was present in methylene structures, contributing almost one half to the organic matter associated with the clay fraction. In progressing from coarse to fine particle size separates, the Aeh horizon showed decreasing ratios carbon-to-nitrogen, and increasing ratios alkyl $\mathrm{C} / O$-alkyl C. Both results supported the hypothesis that decomposition of soil organic matter increased with decreasing particle size. The illuvial Bh horizon contained higher proportions of iron- and aluminum-oxides and hydroxides, and aromatic carbon. Similar proportions of $O$ alkyl C, and smaller proportions of methylene carbon than the Aeh horizon. With decreasing particle size the $\mathrm{C}: \mathrm{N}$ and alkyl $\mathrm{C} / \mathrm{O}$-alkyl $\mathrm{C}$ ratios decreased for the Aeh horizon but not for the the Bh horizon.

Our results suggested that in Bh horizons of Podzols stabilization of organic matter by organo-mineral associations is not limited to aromatic structures; also, presumably, labile structures like polysaccharides can be stabilized.

\section{Acknowledgements}

This work was financially supported by the Deutsche Forschungsgemeinschaft (Ko 1035/6-1 and 2). We thank Professor Dr. Hans-Dietrich Lüdemannn (Universiät Regensburg) for making available NMR instruments. Experimental assistance was provided by Willi Gosda and Gerlind Wilde (Ruhr-Universität Bochum), and figures were prepared by Elfriede Schuhbauer (Technische Universität München). Dr. Jeff Baldock (CSIRO Glen Osmond, Australia) was open for stimulating discussions and provided helpful comments on the manuscript.

\section{References}

AG-Boden, 1994. Bodenkundliche Kartieranleitung, E. Schweizerbart'sche Verlagsbuchhandlung, Stuttgart.

Baldock, J.A., Oades, J.M., Nelson, P.N., Skene, T.M., Golchin, A., Clarke, P., 1997. Assessing the extent of decomposition of natural organic materials using solid-state ${ }^{13} \mathrm{C}$ NMR spectroscopy. Australian Journal of Soil Research 35, 1061-1083.

Baldock, J.A., Oades, J.M., Waters, A.G., Peng, X., Vassallo, A.M., Wilson, M.A., 1992. Aspects of the chemical structure of soil organic materials as revealed by solid-state ${ }^{13} \mathrm{C}$ NMR spectroscopy. Biogeochemistry 16, 1-42.

Catroux, G., Schnitzer, M., 1987. Chemical, spectroscopic, and biological characteristics of the organic matter in particle size fractions separated from an Aquoll. Soil Science Society of America Journal 51, 1200-1207.

Christensen, B.T., 1992. Physical fractionation of soil and organic matter in primary particle size and density separates. Advances in Soil Science 20, 1-90.

Christensen, B.T., 1996. Carbon in primary and secondary organomineral complexes. In: Advances in Soil Science, Springer, pp. 97-165.

Duchaufour, P., 1998. Handbook of Pedology, Balkema Publishers, Rotterdam.

FAO, 1998. FAO-Unesco Soil Map of the World, Revised Legend, FAO, Rome.

Gee, G.W., Bauder, J.W., 1986. Particle size analysis. In: Klute, A. (Ed.), Methods of Soil Analysis, Part 1. American Society of Agronomy, Madison, WI, pp. 383-411.

Guggenberger, G., Zech, W., 1993. Zur Dynamik gelöster organischer Substanzen (DOM) in FichtenökosystemenErgebnisse analytischer DOM-Fraktionierung. Zeitschrift für Pflanzenernährung und Bodenkunde 156, 341-347.

Hempfling, R., Ziegler, F., Zech, W., Schulten, H.-R., 1987. Litter decomposition and humification in acidic forest soils studied by chemical degradation, IR and NMR spectroscopy and pyrolysis field ionization mass spectrometry. Zeitschrift für Pflanzenernährung und Bodenkunde 150, 179-186.

Kaiser, K., Guggenberger, G., 2000. The role of DOM sorption 
to mineral surfaces in the preservation of organic matter in soils. Organic Geochemistry, this issue.

Kaiser, K., Guggenberger, G., Haumeier, L., Zech, W., 1997. Dissolved organic matter sorption on subsoils and soil minerals studied by ${ }^{13} \mathrm{C}-\mathrm{NMR}$ and DRFIT-spectroscopy. European Journal of Soil Science 48, 301-310.

Kaiser, K., Zech, W., 1998. Soil dissolved organic matter sorption as influenced by organic and sesquioxide coatings and sorbed sulfate. Soil Soil Science Society of America Journal 62, 129-136.

Knicker, H. 1993. Quantitative ${ }^{15} \mathrm{~N}$ und ${ }^{13} \mathrm{C}-\mathrm{CPMAS}-F e s t k o ̈ r-$ per und Flüssigkeits-NMR-Spektroskopie an Pflanzenkomposten und natürlichen Böden. In: Biophysik. University of Regensburg, Regensburg

Knicker, H., Schmidt, M.W.I., Kögel-Knabner, I. 2000. Nature of organic nitrogen in fine particle size separates of sandy soils of highly industrialized areas as revealed by NMR spectroscopy. Soil Biology and Biochemistry, 32, 241-252.

Kögel-Knabner, I., 1993. Biodegradation and humification processes in forest soils. In: Bollag, J.-M., Stotzky, G. (Eds.), Soil Biochemistry, Vol. 8. Marcel Dekker, New York, pp. 101-137.

Kögel-Knabner, I., Hatcher, P.G., 1989. Characterization of alkyl carbon in forest soils by CP/MAS 13C NMR spectroscopy and dipolar dephasing. The Science of the Total Environment, 81/ 82, 169-177.

Lüdemann, H.-D., Nimz, H., 1973. ${ }^{13} \mathrm{C}-$ Kernresonanzspektren von Ligninen, 2. Die Makromolekulare Chemie 175, 24092422.

Mahieu, N., Powlson, D.S., Randall, E.W., 1999. Statistical analysis of published carbon-13 CPMAS NMR spectra of soil organic matter. Soil Science Society of America Journal 63, 307-319.

Nierop, K.G.J., 1998. Origin of aliphatic compounds in a forest soil. Organic Geochemistry 29, 1009-1016.

Preston, C.M., Rauthan, B.S., Rodger, C.A., Ripmeester, J.A., 1982. A hydrogen-1, carbon-13 and nitrogen-15 nuclear magnetic resonance study of p-benzoquinone polymers incorporating amino nitrogen compounds ("synthetic humic acids"). Soil Science 134, 277-293.

Preston, C.M., Schnitzer, M., 1984. Effects of chemical modifications and extractants on the C- ${ }^{13}$ NMR spectra of humic materials. Soil Science Society of America Journal 48, 305311.

Preston, C.M., Trofymow, J.A., Sayer, B.G., Niu, J., 1997. ${ }^{13}$ C nuclear magnetic resonance spectroscopy with cross-polariza- tion and magic-angle spinning investigation of the proximate analysis fractions used to assess litter quality in decomposition studies. Canadian Journal of Botany 75, 1601-1613.

Rehfuess, K., 1990. Waldböden, Entwicklung, Eigenschaften und Nutzung, Parey, Hamburg.

Riederer, M., Matzke, K., Ziegler, F., Kögel-Knabner, I., 1993. Inventories and decomposition of the lipid plant biopolymers cutin and suberin in temperate forest soils. Organic Geochemistry 20, 1063-1076.

Schaefer, J., Stejskal, E.O., 1976. Carbon-13 nuclear magnetic resonance of polymers spinning at magic angle. Journal of the American Chemical Society 98, 1031-1032.

Schmidt, M.W.I., Knicker, H., Hatcher, P.G., Kögel-Knabner, I., 1997. Does ultrasonic dispersion and homogenization by ball milling change the chemical structure of organic matter in geochemical samples? - a CPMAS ${ }^{13} \mathrm{C}$ NMR study with lignin. Organic Geochemistry 26, 491-496.

Schmidt, M.W.I., Knicker, H., Hatcher, P.G., Kögel-Knabner, I., 1997. Improvement of ${ }^{13} \mathrm{C}$ and ${ }^{15} \mathrm{~N}$ CPMAS NMR spectra of bulk soils, particle size fractions and organic material by treatment with $10 \%$ hydrofluoric acid. European Journal of Soil Science 48, 319-328.

Schmidt, M.W.I., Rumpel, C., Kögel-Knabner, I., 1999. Evaluation of an ultrasonic dispersion procedure to isolate primary organomineral complexes from soils. European Journal of Soil Science 50, 87-94.

Skjemstad, J.O., Waters, A.G., Hanna, J.V., Oades, J.M., 1992. Genesis of podzols on coastal dunes in Southern Queensland. IV. Nature of the organic fraction as seen by $13 \mathrm{C}$ nuclear magnetic resonance spectroscopy. Australian Journal of Soil Research 30, 667-681.

Sowden, F.J., 1959. Investigations on the amounts of hexosamines found in various soils and methods for their determination. Journal of Soil Science 88, 138-143.

Stevenson, F.J., 1982. Nitrogen-organic forms. In: Page, A.L. (Ed.), Methods of Soil Analysis, Part 2. American Society of Agronomy, Madison, WI, pp. 625-641.

Turchenek, L.W., Oades, J.M., 1979. Fractionation of organomineral complexes by sedimentation and density techniques. Geoderma 21, 311-343.

Watson, J.R., Parsons, J.W., 1974. Studies of soil organomineral fractions; II. extraction and characterization of organic nitrogen compounds. Journal of Soil Science 25, 915.

Wilson, M.A., 1987. NMR Techniques and Applications in Geochemistry and Soil Chemistry, Pergamon Press, Oxford. 